\title{
Vection Is Not Determined by the Retinal Coordinate
}

\author{
Takeharu Seno ${ }^{1,2,3}$ \\ ${ }^{1}$ Faculty of Design, Kyushu University, Fukuoka, Japan \\ ${ }^{2}$ Institute for Advanced Study, Kyushu University, Fukuoka, Japan \\ ${ }^{3}$ Research Center for Applied Perceptual Science, Kyushu University, Fukuoka, Japan \\ Email: seno@design.kyushu-u.ac.jp
}

Received November $6^{\text {th }}$, 2013; revised December $5^{\text {th }}$, 2013; accepted January $3^{\text {rd }}, 2014$

Copyright (C 2014 Takeharu Seno. This is an open access article distributed under the Creative Commons Attribution License, which permits unrestricted use, distribution, and reproduction in any medium, provided the original work is properly cited. In accordance of the Creative Commons Attribution License all Copyrights (C) 2014 are reserved for SCIRP and the owner of the intellectual property Takeharu Seno. All Copyright (C) 2014 are guarded by law and by SCIRP as a guardian.

We examined whether vection was determined by the retinal coordinate. The participants sat on a chair with their body rotated $0,45,90$ and 135 degrees and with their head facing directly at the stimulus screen. Vection strength was changed by rotation of the body. Thus vection was affected by the body coordinate and it was not determined by the retinal coordinate alone.

Keywords: Retinal Coordinate; Head Coordinate; Body Coordinate; Body Rotation

\section{Introduction}

When stationary observers are exposed to a large-field visual motion, simulating the retinal flow generated by self-translation or self-rotation, they often experience an illusory perception of self-motion, known as vection (Fischer \& Kornmuller, 1930). In the history of vection research, various stimulus attributes which are effective or ineffective for vection induction have been examined (e.g. Seno et al., 2009).

One important attribute is in which coordinate vection is determined, whether in the retinal, body, head and/or world coordinates. Morse \& Rieser (2003) reported that vection is strongly determined by the retinal coordinate. Kano (1991) also reported that vection is affected both by retinal and world coordinates. These results suggest that vection is affected by the retinal coordinate.

Other studies reported that vection is affected by vestibular inputs. Young \& Shelhamer (1990) and Mueller \& Kornilova (1994) reported that vection in microgravity condition became unstable and sometimes could be induced in the opposite direction to the normal vection. Lepecq et al. (2006) reported that by adding a vestibular input during vection, the vection direction could be biased intentionally. These results implied that vection was not determined by the retinal coordinate alone.

Nakamura \& Shimojo (1998) reported that the vertical vection was modulated by the body posture whereas the horizontal vection was not modulated by the posture. This result implied that vection is mediated by both retinal and body coordinates.

In this study, we set four different body postures with the same retinal optic flow. The body was rotated horizontally 0,45 , 90 or 135 degrees with the head always directly facing the screen. The participants twisted their head to face the screen. If the vection is determined by the retinal coordinate, the vection strength would be constant for each of the different body postures.
Method

\section{Apparatus}

Stimuli were generated and controlled by a computer (MB543J/A, Apple) and presented on a plasma display (3D Viera, 50 -inch, Panasonic, with $1024 \times 768$ pixel resolution at a $60 \mathrm{~Hz}$ refresh rate). The experiment was conducted in a dark chamber.

\section{Participants}

Sixteen naïve volunteers participated in this experiment. Participants were graduate or undergraduate students. All participants reported normal vision and no history of vestibular system diseases. None of them was aware of the purpose of the experiment.

\section{Stimuli}

Optic flow displays $\left(101^{\circ} \times 80^{\circ}\right.$; presented for $\left.30 \mathrm{~s}\right)$ consisted of about 1000 randomly positioned dots per frame and the global dot motion simulated forwards self-motion $(16 \mathrm{~m} / \mathrm{s})$. The screen size was bigger than that in our previous studies (Seno et al., 2009, 2013). The stimuli were the same as those in Seno (2013a \& 2013b). There was no fixation point in the stimuli. However, the participants were instructed to fixate on the focus of the expansion (FOE). We think that the FOE would be the role of the fixation point.

\section{Procedure}

Participants were asked to press a button when they perceived forward self-motion, and keep the button depressed for the duration of self-motion. After each trial, the participants rated subjective vection strength using a 101-point rating scale ranging from 0 (no vection) to 100 (very strong vection). 
There were four conditions in participants' body posture. The head was always fixed facing straight at the screen but the body was rotated 0, 45, 90 and 135 degrees by rotating the subject's chair (Figure 1). We believe that even with maximum rotation of the body, the participants still could gaze the stimuli as correctly as the experimenter intended. The experimenter observed, checked and confirmed that the participants could do that during the experiment (Please check the Figure 1).

\section{Result and Discussion}

The results were shown in Figure 2. The latency was the shortest in the 0 degree condition and it became longer as the degree of rotation was increased. The duration and magnitude were the longest and largest in the 0 degree condition and it became shorter and smaller as the rotation was increased. One-way ANOVA revealed a significant main effect of the body rotation in all three measures (latency, $\mathrm{F}(3,45)=3.64, p$ $<0.05$; duration, $\mathrm{F}(3,45)=7.72 p<0.01$; magnitude, $\mathrm{F}(3,45)=$ $4.32, p<0.01)$. Multiple comparisons revealed significant differences between the 0 degree condition and the other three rotated conditions (Holm, $\mathrm{p}<0.05$ ). The obtained vection in the 0 degree condition was stronger than the vection obtained by the same stimuli in our previous studies (e.g. Seno, et al., 2011). This is related the fact that in this study we used lager stimulus $\left(101^{\circ} \times 80^{\circ}\right)$ than that in the previous study $\left(72^{\circ} \times 57^{\circ}\right)$. The vection was the strongest when the body and the head directions were the same. When the discrepancy between the head and the body positions was increased, vection strength was weakened. Thus vection was determined less by the retinal coordinate but is significantly more affected by the body coordinate. We speculate that vection is determined by the output from the integration of multiple coordinates.

We should do the same experiment using visual rotation along with yaw axis in the future. We obtained the subjective direction of vection in this experiment by oral report after finishing the whole experimental procedure. The participants mainly reported the forward self-motion to the stimuli, i.e. moving into the display. Thus the direction of the head determined and dominated the direction of the self-motion. However, further examination for this problem should be needed. This will be a very important topic of this field.

In fact, there was the possibility that in the condition of extreme rotation (e.g. 135 degree), the observers might have continuous efforts to maintain such an unnatural posture, and then, their attention would be deprived from the vection task. Vection induction requires attentional resources (Seno et al., 2011). When the attention was deprived, vection should be weaker. In this study we could not deny this possibility. In future examinations, we should control the deprived attentional resources by the different postures.

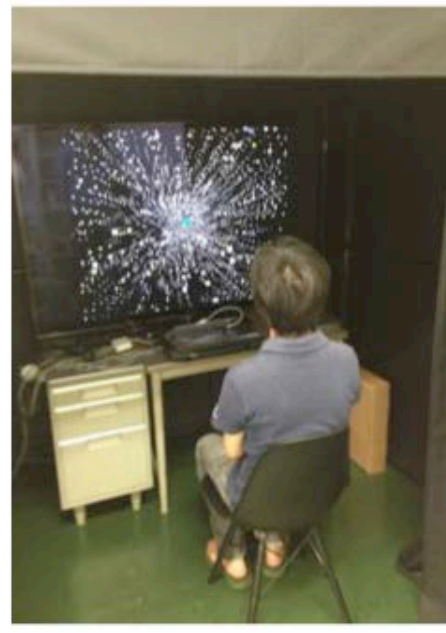

0 deg condition

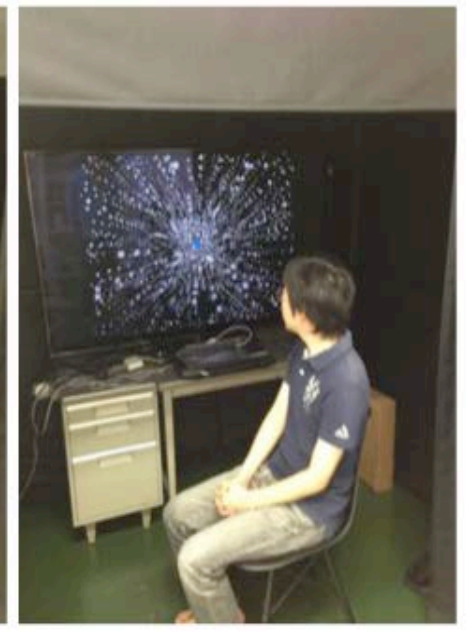

90 deg condition

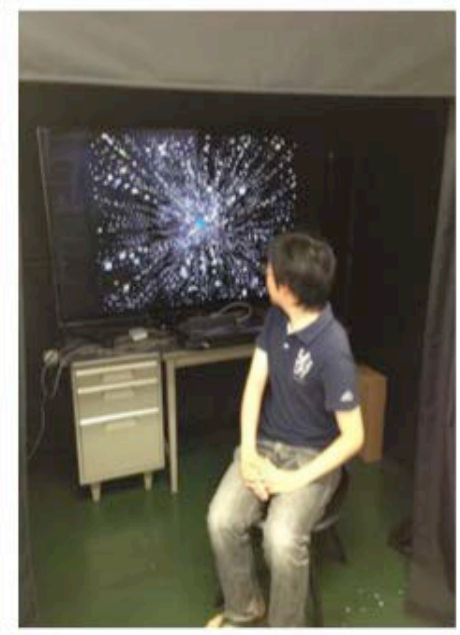

135 deg condition

Figure 1.

The postures of the participants who viewed the optical flows.
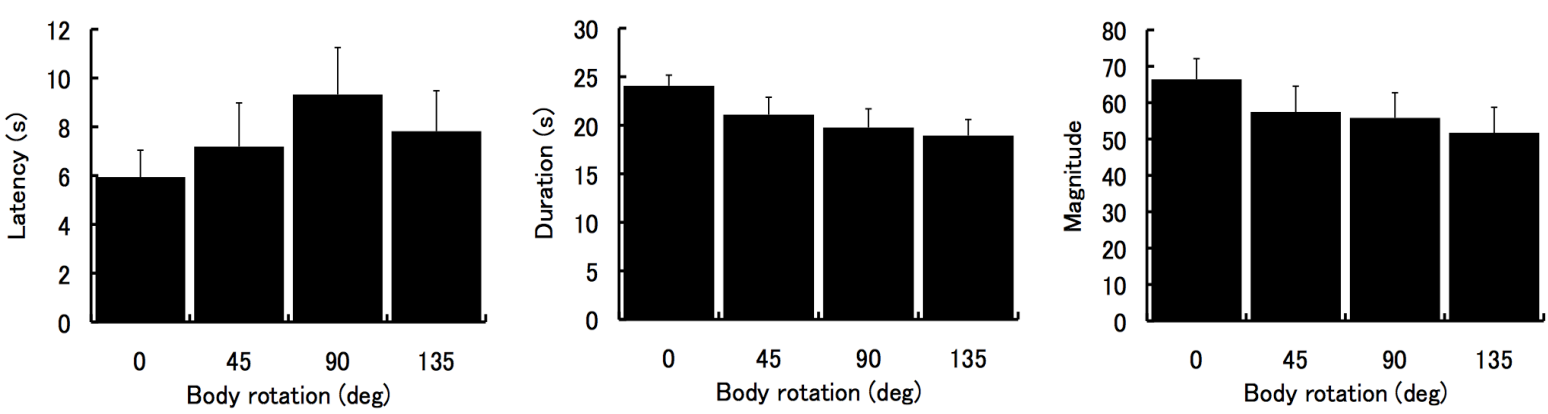

Figure 2.

Results of vection strength (latency, duration and magnitude). Error bars indicate SEs. 


\section{Acknowledgements}

This work is supported by Program to Disseminate TenureTracking System, MEXT, Japan.

\section{REFERENCES}

Fischer, M. H., \& Kornmüller, A. E. (1930). Optokinetischausgelöstebewegungswahrnehmungen und optokinetischernystagmus. Journal fürPsychologie und Neurologie (Leipzig), 41, 273-308

Kano, C. (1991). The perception of self-motion induced by peripheral visual information in sitting and supine postures. Ecological Psychology, 3, 241-252. http://dx.doi.org/10.1207/s15326969eco0303_3

Lepecq, J. C., De Waele, C., Mertz-Josse, S., Teyssèdre, C., Tram BaHuy, P., Baudonnière, P. M., \& Vidal, P. P. (2006). Galvanic vestibular stimulation modifies vection path in healthy subjects. Journal of Neurophysiology, 95, 3199-3207. http://dx.doi.org/10.1152/jn.00478.2005

Morse, D. L., \& Rieser, J. J. (2003). Linear vection shows a retinal frame of reference. Journal of Vision, 3, 493.

http://dx.doi.org/10.1167/3.9.493

Mueller, C. H., Kornilova, L., Wiest, G., \& Steinhoff, N. (1994). Psychophysical studies of visuo-vestibular interaction in microgravity. Acta Astronautica, 33, 9-13. http://dx.doi.org/10.1016/0094-5765(94)90102-3

Nakamura, S., \& Shimojo, S. (1998). Orientation of selective effects of body tilt on visually induced perception of self-motion. Perceptual and Motor Skills, 87, 667-672.

http://dx.doi.org/10.2466/pms.1998.87.2.667

Seno, T., Ito, H., \& Sunaga, S. (2009). The object and background hypothesis for vection. Vision Research, 49, 2973-2982. http://dx.doi.org/10.1016/j.visres.2009.09.017

Seno, T., Kawabe, T., Ito., H. \& Sunaga, S. (2013). Vection modulates emotional valence of autobiographical episodic memories. Cognition, 126, 115-120. http://dx.doi.org/10.1016/j.cognition.2012.08.009

Seno, T., Ito, H., \& Sunaga, S. (2011). Inconsistent locomotion inhibits vection. Perception, 40, 747-750. http://dx.doi.org/10.1068/p7018

Seno, T., Ito, H., \& Sunaga, S. (2011). Attentional load inhibits vection. Attention, Perception \& Psychophysics, 73, 1467-1476. http://dx.doi.org/10.3758/s13414-011-0129-3

Seno, T. (2013). Social inhibition of vection. Psychology, Scientific Research, 4, 619-621.

Seno, T. (2013). Music enhances vection. Psychology, Scientific Research, 7, 566-568.

Young, L. R., \& Shelhamer, M. (1990). Microgravity enhances the relative contribution of visually-induced motion sensation. Aviation, Space, and Environmental Medicine, 61, 525-530. 